Revista Brasileira de Agricultura Irrigada v.12, nº.3, p. 2604 - 2612, 2018

ISSN 1982-7679 (On-line)

Fortaleza, CE, INOVAGRI - http://www.inovagri.org.br

DOI: $10.7127 /$ rbai.v12n300722

Protocolo 722.18 - 19/07/2017 Aprovado em 03/04/2018

\title{
PRODUÇÃO DE GIRASSOL IRRIGADO COM ÁGUA RESIDUÁRIA SOB ADUBAÇÃO INORGÂNICA ${ }^{1}$
}

Helder Morais Mendes Barros ${ }^{2}$, Hans Raj Gheyi ${ }^{3}$, Kaline Dantas Travassos ${ }^{4}$, Nildo da Silva Dias $^{5}$, Mara Karinne Lopes Veriato Barros ${ }^{6}$, Moadir de Sousa Leite ${ }^{7}$

\section{RESUMO}

Objetivou-se com o presente trabalho avaliar a produção do girassol (Helianthus annuus L., cv. Catissol 01) sob o efeito de irrigação com água de abastecimento $\left(\mathrm{A}_{1}\right)$ e efluente de esgoto tratado $\left(\mathrm{A}_{2}\right)$ associada à adubação inorgânica, em ambiente protegido na Universidade Federal de Campina Grande Campus I, em Campina Grande, PB. O delineamento experimental adotado foi inteiramente casualizado e os tratamentos constaram de dosagens de adubação inorgânica (D1:60; D2: 80; D3: 100; D4: 120 e D5: 140\% da dose de N recomendada para a cultura) e duas fontes de irrigação ( $\mathrm{A}_{1}$ e $\mathrm{A}_{2}$ ) em esquema fatorial 5 x 2 com 5 repetições, totalizando 50 unidades experimentais. As variáveis analisadas foram: fitomassa fresca da parte aérea (FFPA), fitomassa seca da parte aérea (FSPA), número de pétalas (NP), diâmetro interno do capítulo (DI), diâmetro externo do capítulo (DE), peso de aquênios (PA), número total de aquênios (NA) e peso de 100 aquênios (P100A). A água residuária demonstrou eficácia para a irrigação do girassol cv. Catissol 01, uma vez que as principais variáveis de produção não foram afetadas pela sua utilização, podendo ser utilizada para a irrigação desta cultura.

Palavras-chave: reuso de água, desenvolvimento, nitrogênio

\section{SUNFLOWER PRODUCTION IRRIGATED WITH RESIDUE WATER UNDER INORGANIC FERTILIZATION}

\footnotetext{
ABSTRACT

The objective of this study was to evaluate the production of sunflower (Helianthus annuus L., Catissol 01) under the effect of irrigation with water supply $\left(\mathrm{A}_{1}\right)$ and treated sewage effluent

${ }^{1}$ Parte da tese do primeiro autor

${ }^{2}$ Doutor em Engenharia Agrícola. Universidade Federal de Campina Grande, e-mail: hmmbbr@yahoo.com.br

${ }^{3}$ Engenheiro Agrônomo, Universidade Federal do Recôncavo Baiano, e-mail: hans@agriambi.com.br

${ }^{4}$ Doutora em Engenharia Agrícola, Universidade Federal Rural do Semi-Árido, e-mail: kalinedantas@yahoo.com.br

${ }^{5}$ Doutor em ciência do solo, Universidade Federal Rural do Semi-Árido, e-mail: nildo@ufersa.edu.br

${ }^{6}$ Mestre em recursos naturais, Universidade Federal de Campina Grande, e-mail: karinnejus@yahoo.com.br

${ }^{7}$ Engenheiro Agrônomo, Universidade Federal Rural do Semi-Árido, e-mail: moadir@outlook.com
} 
$\left(A_{2}\right)$ associated with inorganic fertilization in the environment protected at the Federal University of Campina Grande Campus I, Campina Grande, PB. The experimental design was completely randomized and the treatments consisted of dosages of inorganic fertilization $\left(\mathrm{D}_{1}\right.$ : 60, D2: 80, D3: 100, D4: 120 and $D_{5}: 140 \%$ of the recommended $N$ dose for the crop) and two sources of irrigation ( $\mathrm{A}_{1}$ and $\mathrm{A}_{2}$ ) in a $5 \times 2$ factorial scheme with 5 replications, totaling 50 experimental units. The variables analyzed were: fresh shoot biomass (FSB), dry shoot biomass (DSB), number of petals (NP), internal diameter of the chapter (DI), external diameter of the chapter (IDC), weight of achenes (WA), total number of achenes (TNA) and weight of 100 achens (W100A). The wastewater showed efficacy for the irrigation of sunflower cv. Catissol 01, since the main production variables were not affected by their use, and can be used for the irrigation of this crop.

Keywords: water reuse, development, nitrogen

\section{INTRODUÇÃO}

O girassol (Helianthus annuus L.) é uma dicotiledônea anual originária da América do Norte (ZOBIOLE et al., 2010) que pertence à família Asteraceae, sendo uma cultura que se destaca pela elevada produtividade de óleo, produção melífera e também por ser utilizada como fonte de farelo ou mesmo de silagem para a alimentação animal (ANDRADE et al., 2014). Esta oleaginosa apresenta características agronômicas importantes, como resistência à seca, ao frio e ao calor, assim como a maioria das oleaginosas normalmente cultivadas no Brasil (LEITE et al., 2007), principalmente na região Nordeste do país (TALAMINI et al., 2011).

O girassol é pouco exigente em água, porém seu desenvolvimento é alterado em caso de déficit hídrico. A água é um fator limitante para a produção agrícola, e a disponibilidade hídrica, sobretudo para a região semiárida que possui precipitações irregulares, pode comprometer a produção agrícola significativamente (SANTOS et al., 2009).

O reúso de águas para a irrigação é uma prática amplamente estudada e recomendada por vários pesquisadores como alternativa viável para suprir as necessidades hídricas e, em grande parte, nutricionais das plantas (HERPIN et al., 2007). Em trabalhos onde testou-se a viabilidade da utilização de água de reuso doméstico na irrigação da cultura, Andrade et al., (2012); Freitas et al., (2012) observaram que a água de esgoto tratada não prejudicou a qualidade das flores do girassol.
Porém, quando se utiliza água residuária tratada na agricultura, apesar da carga de nutrientes disponível, nem sempre são suficientes para atender a demanda nutricional da cultura explorada e, geralmente, há necessidade de complementação de adubação mineral para garantir a boa produtividade da cultura.

Diante do exposto, o presente estudo tem como objetivo avaliar o desempenho e produção do girassol irrigado com água de abastecimento e residuária tratada associada à adubação inorgânica.

\section{MATERIAL E MÉTODOS}

O experimento foi conduzido em casa de vegetação da Unidade Acadêmica de Engenharia Agrícola, do Centro de Tecnologia e Recursos Naturais da Universidade Federal de Campina Grande, Campus I, Campina Grande, $\mathrm{PB}$, cuja localização é dada pelas coordenadas geográficas $7^{\circ} 15^{\prime} 18^{\prime \prime} \mathrm{S}$ e $35^{\circ} 52^{\prime} 28^{\prime \prime} \mathrm{W}$ com altitude de 550 m (COELHO; SONCIN, 1982).

Avaliou-se o efeito da irrigação com água de abastecimento $\left(\mathrm{A}_{1}\right)$ e efluente de esgoto municipal $\left(\mathrm{A}_{2}\right)$ combinados com cinco doses de adubo inorgânico: $\mathrm{D}_{1}$ : 60; $\mathrm{D}_{2}$ : 80; $\mathrm{D}_{3}$ : 100; $\mathrm{D}_{4}$ : 120 e D5: $140 \%$ da dose de nitrogênio recomendada por Novais et al., (1991), na produção e componentes de rendimento do girassol.

Os tratamentos foram dispostos em blocos inteiramente casualizados, em esquema fatorial $5 \times 2$, com 5 repetições, totalizando 50 unidades experimentais. $\mathrm{O}$ arranjo do 
experimento foi triangular em fileiras duplas, espaçadas em 0,60 m entre fileira simples, 0,50 $\mathrm{m}$ entre plantas de cada fileira e $1,00 \mathrm{~m}$ entre fileiras duplas. Utilizou-se a cv. Catissol 01 de girassol, cedido pela Coordenadoria de Assistência Técnica Integral - CATI, através do Núcleo de Produção de Sementes "Ataliba Leonel", do Departamento de Sementes, Mudas e Matrizes - DSMM - São Paulo.

A água de abastecimento $\left(\mathrm{A}_{1}\right)$ foi oriunda do sistema de abastecimento de Campina Grande-PB (CAGEPA), proveniente do açude público Epitácio Pessoa (Açude de Boqueirão). A água residuária tratada $\left(\mathrm{A}_{2}\right)$ utilizada na irrigação do experimento foi originária do córrego de Monte Santo (bairro da cidade de
Campina Grande), esgoto de origem doméstica, onde foi captada e tratada, primeiro com um tratamento primário, no fundo de um poço de cimento, brita e areia, em seguida bombeada para o Reator Anaeróbio de Manta de Lodo (UASB - Upflow Anaerobic Sludge Blanket); depois foi tratada pelo sistema de wetland, lagoa de estabilização. Após o tratamento a água residuária foi bombeada para um reservatório de $5000 \mathrm{~L}$ de capacidade localizado no interior da casa de vegetação, de onde era utilizada na irrigação das parcelas. As águas $\left(\mathrm{A}_{1} \mathrm{eA}_{2}\right)$ foram analisadas no Laboratório de Irrigação e Salinidade (LIS) da UFCG, seguindo as metodologias propostas pela EMBRAPA (1997) (Tabela 1).

Tabela 1. Análise química das águas utilizadas no experimento.

\begin{tabular}{|c|c|c|}
\hline Análise química de águas & Água de abastecimento & Água residuária tratada \\
\hline $\mathrm{pH}$ & 7,47 & 7,31 \\
\hline Condutividade elétrica ( $\mathrm{dS} \mathrm{m}^{-1}$ ) & 0,39 & 1,39 \\
\hline Cálcio (meq L ${ }^{-1}$ ) & 1,00 & 3,88 \\
\hline Magnésio (meq L ${ }^{-1}$ ) & 1,30 & 4,44 \\
\hline Sódio (meq L L-1) & 1,55 & 5,50 \\
\hline Potássio (meq $\mathrm{L}^{-1}$ ) & 0,14 & 0,82 \\
\hline Carbonatos (meq $\mathrm{L}^{-1}$ ) & 0,00 & 1,60 \\
\hline Bicarbonatos (meq L-1) & 1,30 & 6,83 \\
\hline Cloretos (meq L ${ }^{-1}$ ) & 2,21 & 8,47 \\
\hline Sulfatos (meq $\mathrm{L}^{-1}$ ) & Ausência & Presença \\
\hline Relação de adsorção de sódio (RAS) & 1,94 & 2,70 \\
\hline Classe de água & $\mathrm{C}_{2}$ & $\mathrm{C}_{3}$ \\
\hline
\end{tabular}

O solo utilizado foi classificado como Neossolo Regolítico Distrófico, tipo francoarenoso, não salino e não sódico, coletado na camada superficial $(0-20 \mathrm{~cm})$, proveniente do distrito de São José da Mata, município de Campina Grande.

Utilizaram-se vasos plásticos com 36,5 cm de diâmetro, $30 \mathrm{~cm}$ de altura e com capacidade de $20 \mathrm{~L}$, os quais foram perfurados na base inferior com vista à instalação de um conector de $1 / 2$ polegada, para a coleta da água drenada interligado a um recipiente externo com $2 \mathrm{~L}$ de capacidade. Os vasos foram preenchidos com $20 \mathrm{Kg}$ de solo, sendo realizada adubação de fundação (300 mg kg-1 de $\mathrm{P}_{2} \mathrm{O}_{5}$ ). Após a identificação dos vasos, os mesmos foram levados à capacidade de campo com a respectiva água do tratamento.
Foram semeadas 10 sementes por vaso, sendo realizado o desbaste 10 dias após o plantio, mantendo-se 3 plantas por vaso. A irrigação $\left(A_{1}\right.$ e $\left.A_{2}\right)$ foi realizada diariamente desde o semeio, buscando-se a manutenção da capacidade de campo ao longo da condução do experimento.

As adubações inorgânicas foram feitas em cobertura seguindo a recomendação de Novais et al. (1991), divididas em três aplicações 10, 20 e 30 DAP, em dosagens de 1,72 g de $\mathrm{K}_{2} \mathrm{SO}_{4}$ por vaso, variando a fonte de $\mathrm{N}$ ureia para cada tratamento, aplicando-se em círculo com distância de $5 \mathrm{~cm}$ da planta.

As variáveis analisadas foram: fitomassa fresca da parte aérea (FFPA), fitomassa seca da parte aérea (FSPA), número de pétalas (NP), diâmetro interno do capítulo (DI), diâmetro externo do capítulo (DE), peso de aquênios 
(PA), número total de aquênios (NA) e peso de 100 aquênios (P100A).

Com vista à medição dos diâmetros, utilizou-se uma régua graduada sendo o diâmetro interno medido pela parte fertilizada do receptáculo floral, enquanto que para o diâmetro externo foram medidas as duas extremidades das pétalas, cruzando no centro do capítulo. A contagem do número de pétalas (NP) foi feita na época da medição dos diâmetros, metodologia esta proposta por Andrade et al., (2014).

Para determinar o peso dos aquênios utilizou-se uma balança digital eletrônica com precisão de $0,001 \mathrm{~g}$, na qual também foi realizada a determinação do peso de 100 aquênios, sendo estes escolhidos aleatoriamente; e por fim, fez-se a contagem total dos aquênios.

Ao final do experimento, as plantas de girassóis foram coletadas e determinou-se a fitomassa fresca da parte aérea (FFPA) através da pesagem do material em balança digital eletrônica com precisão de 0,001 g. Após a pesagem, o material foi acondicionado em sacos de papel e levado à estufa de circulação de ar quente, a $65^{\circ} \mathrm{C}$, até peso constante, para determinação da fitomassa seca da parte aérea (FSPA), através da pesagem do material em balança digital eletrônica com precisão de $0,001 \mathrm{~g}$.

Os dados obtidos foram submetidos à análise de variância e as águas comparadas pelo teste de Tukey $(\mathrm{p}<0,05)$. Utilizou-se o programa estatístico SISVAR (FERREIRA, 2011). Realizou-se ainda a transformação dos dados das variáveis FFPA, PA e NA (em raiz de $x+1$ ), seguindo-se o critério de reduzir o coeficiente de variação, mantendo abaixo de $20 \%$, utilizando-se a menor transformação possível.

\section{RESULTADOS E DISCUSSÃO}

Com base na análise de variância, verificou-se que a fitomassa fresca da parte aérea (FFPA) e a fitomassa seca da parte aérea (FSPA) foram influenciadas significativamente pela água de irrigação, enquanto que para a adubação inorgânica, não houve efeito significativo $(\mathrm{p}<0,05)$ (Tabela 2$)$.

Tabela 2. Resumo da Anova para fitomassa fresca da parte aérea (FFPA) e fitomassa seca da parte aérea (FSPA) de girassóis em função da água de irrigação e da adubação inorgânica.

Fonte de Variação

Quadrados Médios

\begin{tabular}{cccc}
\cline { 3 - 4 } & GL & FFPA\# & FSPA \\
\hline Água (A) & 1 & $9,058^{*}$ & $91,530^{*}$ \\
Ad. inorgânica (I) & 4 & $1,055^{\mathrm{ns}}$ & $33,795^{\mathrm{ns}}$ \\
Interação AxI & 4 & $0,414^{\mathrm{ns}}$ & $10,543^{\mathrm{ns}}$ \\
Resíduo & 40 & 1,655 & 18,108 \\
CV \% & - & 18,53 & 14,86 \\
\hline
\end{tabular}

GL = grau de liberdade; $\mathrm{CV}$ = coeficiente de variação; ${ }^{*}=$ significativo a 0,05 de probabilidade; ${ }^{\text {ns }}=$ não significativo. \# Dados transformados em $\sqrt{x+1}$

Verificou-se que as médias para FFPA e FSPA de plantas irrigadas com efluente doméstico tratado foram superiores às irrigadas com água de abastecimento (Figura 1). Dessa forma, a utilização de água residuária na irrigação do girassol foi benéfica, uma vez que a produção de biomassa da parte aérea é de grande importância por ser uma alternativa utilizada na produção de silagem para a alimentação animal (ANDRADE et al., 2014). 

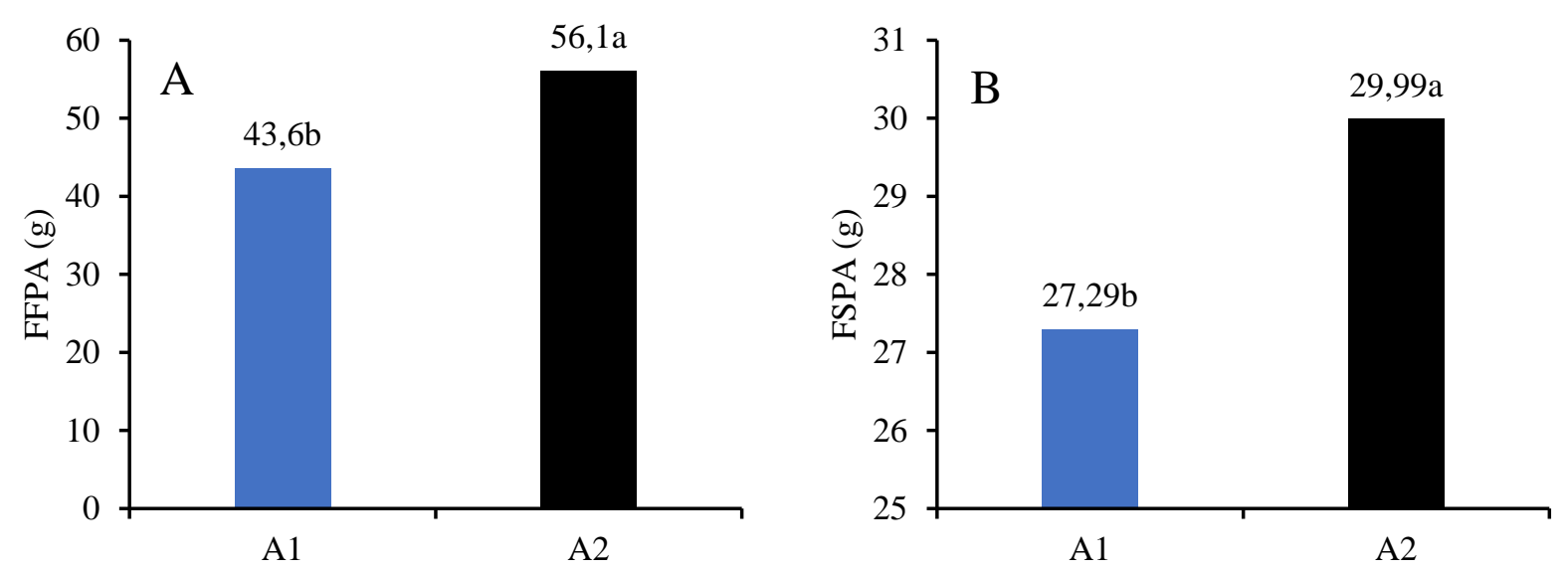

Figura 1. Fitomassa fresca da parte aérea (FFPA) e fitomassa seca da parte aérea (FSPA) de girassóis em função da irrigação com água de abastecimento $\left(\mathrm{A}_{1}\right)$ e água residuária $\left(\mathrm{A}_{2}\right)$.

Os efluentes domésticos tratados como as águas residuárias possuem efeito fertilizante sobre a cultura do girassol, tornando-se uma alternativa relevante na adoção de prática de fertirrigação, sobre maneira de culturas cujos produtos não se destinam ao consumo humano.

Diversos experimentos com o cultivo do girassol vêm sendo desenvolvidos, como por exemplo os realizados por Andrade et al., (2007), Nobre et al., (2008), Souza (2010), Silva et al., (2012) e outros, comprovando a eficiência do uso da água residuária como instrumento de irrigação, uma vez que esta não afeta negativamente o desenvolvimento das plantas em relação à irrigação tradicional, além de suprir as necessidades hídricas da cultura, servindo ainda como fonte de nutrientes para o seu desenvolvimento.

Não foi verificado efeito significativo $(\mathrm{p}<0,05)$ entre número de pétalas (NP), diâmetro interno (DI) e diâmetro externo (DE) do capítulo do girassol em função da água de irrigação e da adubação inorgânica (Tabela 3), indicando que estas variáveis se comportam de maneira semelhante independentemente da dose de adubo inorgânico e da água de irrigação utilizada.

Tabela 3. Resumo da Anova para número de pétalas (NP), diâmetro interno (DI) e diâmetro externo (DE) do capítulo de girassóis em função da água de irrigação e da adubação inorgânica.

\begin{tabular}{ccccc}
\hline \multirow{2}{*}{ Fonte de Variação } & \multicolumn{4}{c}{ Quadrados Médios } \\
\cline { 2 - 5 } & GL & NP & DI (cm) & DE (cm) \\
\hline Água (A) & 1 & $8.820^{\mathrm{ns}}$ & $0.845^{\mathrm{ns}}$ & $1.549^{\mathrm{ns}}$ \\
Ad. inorgânica (I) & 4 & $6.850^{\mathrm{ns}}$ & $0.970^{\mathrm{ns}}$ & $6.531^{\mathrm{ns}}$ \\
Interação AxI & 4 & $7.670^{\mathrm{ns}}$ & $1.003^{\mathrm{ns}}$ & $2.851^{\mathrm{ns}}$ \\
Resíduo & 40 & 7.290 & 1.287 & 2.874 \\
CV \% & - & 8.01 & 11.26 & 7.91 \\
\hline
\end{tabular}

GL = grau de liberdade; $\mathrm{CV}$ = coeficiente de variação; ${ }^{\text {ns }}=$ não significativo.

De forma semelhante ao observado no presente estudo, Morales et al., (2015) e Soares et al., (2016) observaram que o diâmetro do capítulo (DC) não foi afetado pela adubação nitrogenada $(\mathrm{P}>0,05)$, denotando ausência de relação deste nutriente com a variável. Já Biscaro et al., (2008) avaliando a resposta da cultura do girassol irrigado em diferentes doses de nitrogênio, constataram que a aplicação de $\mathrm{N}$ até a dosagem de $44,9 \mathrm{~kg} \mathrm{ha}^{-1}$ resultou em aumento do diâmetro externo do capítulo, fato que não foi verificado no presente estudo.

Corroborando os resultados encontrados para NP, Andrade et al., (2014) avaliando a qualidade de flores de girassol ornamental irrigado com água residuária e de 
abastecimento, não observaram diferenças significativas para esta variável entre os tipos de água, indicando que a água residuária pode ser utilizada na irrigação do girassol ornamental, sem redução do NP, que é um componente de rendimento de importância para a cultura do girassol.

O diâmetro do capítulo é outra variável de grande importância para a cultura do girassol, pois tem elevada correlação com o peso do grão e a produtividade, além de ser de fácil medição e com alta predição (SOARES et al., 2016). Com base em ensaio realizado com a cultura do girassol, Lobo e Grassi Filho (2007) citam que é possível substituir o nitrogênio proveniente de adubação mineral por $\mathrm{N}$ contido em fontes alternativas, como o lodo de esgoto, constantemente presente em águas de reuso doméstico, devido ao aumento do diâmetro do capítulo obtido no experimento.
Alicerçando na recomendação de Sabbagh (2008) ao relatar que, embora não haja uma classificação oficial quanto à padronização do diâmetro de capítulo no mercado da floricultura de Curitiba, o diâmetro capitular deve ter em média 12 - $16 \mathrm{~cm}$; pode-se então, constatar que o DE das flores de girassol obtido neste experimento, está acima dos padrões comerciais.

Na análise de variância para peso de aquênios (PA), número total de aquênios (NA) e peso de 100 aquênios (P100A), em função da água de irrigação e da adubação inorgânica (Tabela 4), observa-se que não houve efeito significativo para as doses de adubação inorgânica (I). Já para a água de irrigação (A), obteve-se efeito significativo para as variáveis peso de aquênios (PA) e número total de aquênios (NA).

Tabela 4. Resumo da Anova para peso de aquênios (PA), número total de aquênios (NA) e peso de 100 aquênios (P100A) de girassóis em função da água de irrigação e da adubação inorgânica.

\begin{tabular}{ccccc}
\hline & & \multicolumn{3}{c}{ Quadrados Médios } \\
\cline { 3 - 5 } Fonte de Variação & GL & PA (g)\# & NA\# & P100A (g) \\
\hline Água (A) & 1 & $8,390^{*}$ & $139,660^{*}$ & $8,032^{\text {ns }}$ \\
Ad. inorgânica (I) & 4 & $0,285^{\text {ns }}$ & $1,160^{\text {ns }}$ & $0,572^{\text {ns }}$ \\
Interação AxI & 4 & $0,558^{\text {ns }}$ & $6,081^{\text {ns }}$ & $11,815^{*}$ \\
Resíduo & 40 & 0,513 & 16,364 & 3,03 \\
CV \% & - & 14,12 & 18,82 & 24,4 \\
\hline
\end{tabular}

GL = grau de liberdade; $\mathrm{CV}=$ coeficiente de variação; *= significativo a 0,05 de probabilidade; ${ }^{\text {ns }}=$ não significativo. $\#$ Dados transformados em $\sqrt{x+1}$

Para o peso de aquênios (PA) e número total de aquênios (NA), os melhores resultados foram obtidos com a irrigação com água residuária $\left(A_{2}\right)$, havendo incrementos de $29 \%$ para o peso de aquênios (PA) e 25\% para o número total de aquênios (NA) em relação às plantas mantidas sob irrigação com água de abastecimento (Figura 2). 

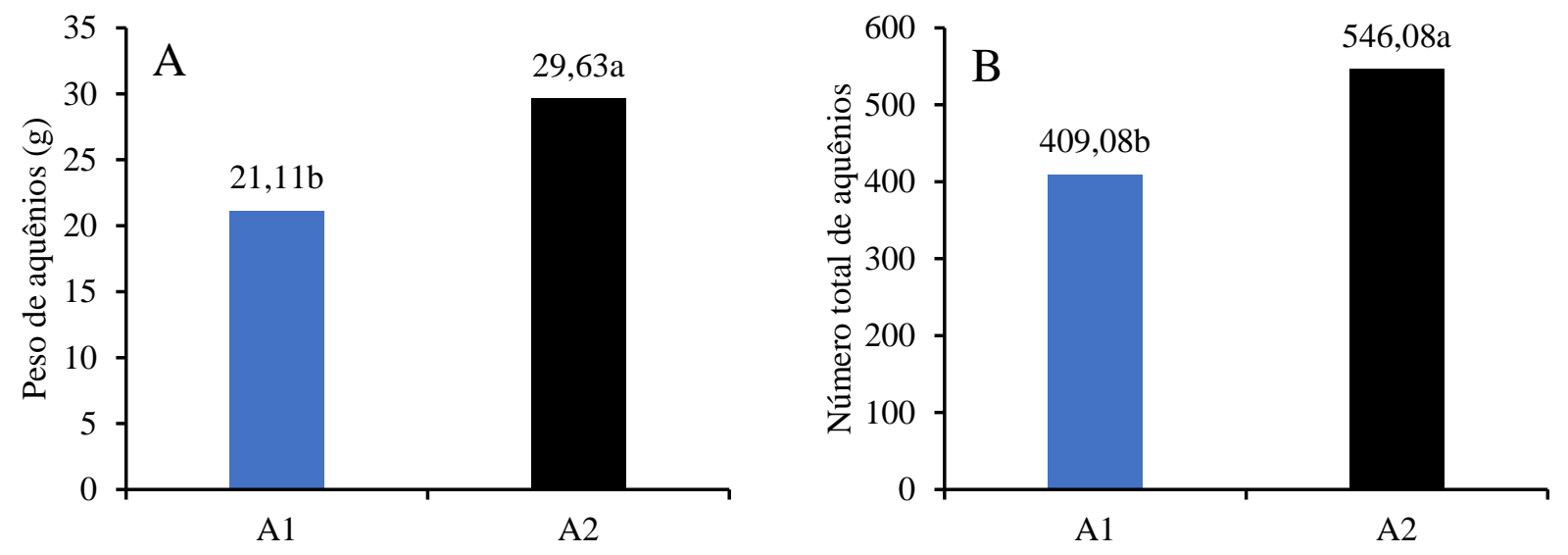

Figura 2. Peso de aquênios (PA) número total de aquênios (NA) em função da irrigação com água de abastecimento $\left(\mathrm{A}_{1}\right)$ e água residuária $\left(\mathrm{A}_{2}\right)$.

Lobo e Grassi Filho (2007) verificaram maior produção de sementes nos tratamentos com águas residuárias em comparação com a adubação mineral e com a testemunha sem adubação, podendo ser a água residuária utilizada alternativamente para a substituição da adubação tradicional, havendo incrementos, em termos de rendimento, quando comparado com a adubação mineral.

Para a interação entre a água de irrigação e a adubação inorgânica (Figura 3), observouse efeito significativo para o peso de 100 aquênios (P100A). O menor valor para esta variável (5,6 g) foi obtido quando o girassol foi cultivado com a dose de $60 \%$ de $\mathrm{N}$ e irrigado com água de abastecimento, e o maior valor $(8,6 \mathrm{~g})$ obtido quando as plantas foram cultivadas com a dose de $140 \%$ de $\mathrm{N}$ e irrigado com água residuária. Embora os melhores resultados para esta variável tenham sido obtidos com a dose de $140 \%$ de $\mathrm{N}$ e irrigação com água residuária, não é possível apontar a viabilidade econômica da aplicação desta dosagem de N, uma vez que as plantas adubadas com apenas $60 \%$ da dose recomendada de $\mathrm{N}$ e irrigadas com água residuária obtiveram um valor para P100A (8,4 g) muito próximo ao máximo encontrado (8,6 g), havendo, dessa forma, um incremento de apenas $2,3 \%$ no P100A com a elevação da dose de 60 para $140 \%$ de $\mathrm{N}$.

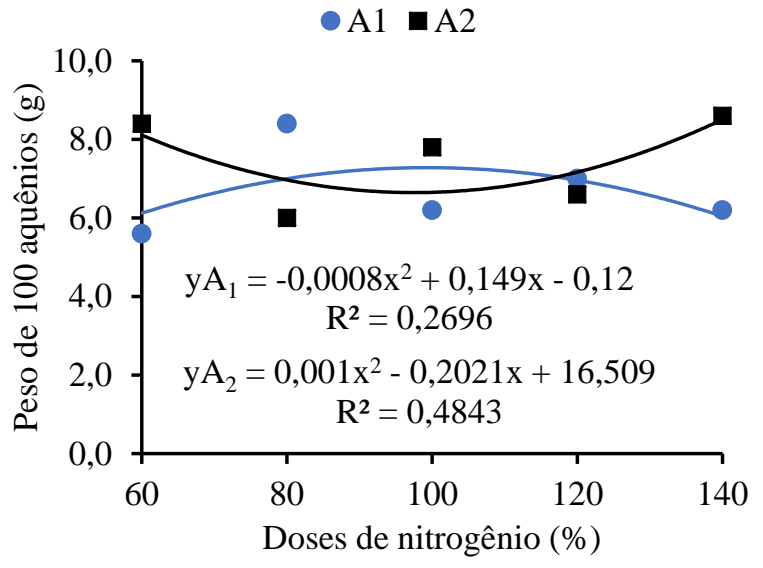

Figura 3. Peso de 100 aquênios (P100A) em função da irrigação com água de abastecimento $\left(\mathrm{A}_{1}\right)$ e água residuária $\left(\mathrm{A}_{2}\right)$ e da adubação inorgânica.

Avaliando o efeito da utilização de água salobra para irrigação na produção de aquênio do girassol, Travassos et al., (2011) não observaram redução no P100A quando o girassol foi irrigado com água salobra de até CEa de 2,0 dS m${ }^{-1}$, indicando que a água de reuso utilizada no presente estudo (CEa: 1,39 $\mathrm{dS} \mathrm{m}^{-1}$ ) pode ser utilizada como alternativa à irrigação do girassol, sem causar redução no peso de aquênios.

O peso de aquênio é o resultado da capacidade da planta de suprir nutrientes até o limite potencial estabelecido para cada cultivar (BISCARO et al., 2008). Em geral, há uma grande diversidade de respostas especialmente associadas ao número de aquênios previamente fixados (ZAGONEL; MUNDSTOCK, 1991). 


\section{CONCLUSÕES}

A água residuária demonstrou eficácia para a irrigação do girassol cv. Catissol 01, uma vez que as principais variáveis de produção não foram afetadas pela sua utilização, podendo ser utilizada para a irrigação desta cultura.

A utilização de água residuária provocou incrementos no rendimento de biomassa da parte aérea e rendimento de aquênios do girassol cv. Catissol 01.

\section{REFERÊNCIAS BIBLIOGRÁFICAS}

ANDRADE, L.O.; GHEYI, H. R.; DIAS, N. S.; NOBRE, R. G.; SOARES, F. A. L.; NASCIMENTO, E. C. S. Qualidade de flores de girassol ornamental irrigada com água residuária e doses de esterco. Revista Caatinga, v. 27, n. 3, p. 142 - 149, 2014. https://periodicos.ufersa.edu.br/index.php/caati nga/article/view/2788/pdf_148

ANDRADE, L. O.; GHEYI, H. R.; NOBRE, R. G.; DIAS, N. S.; NASCIMENTO, E. C. S. Qualidade de flores de girassóis ornamentais irrigados com águas residuária e de abastecimento. Idesia, v. 30, n. 2, p. 19-27, $2012 . \quad$ http://dx.doi.org/10.4067/S071834292012000200003

ANDRADE, L. O.; NOBRE, R. G.; SOARES, F. A. L.; GHEYI, H. R.; FIGUEIREDO, G. R. G.; SILVA, L. A. Germinação e crescimento inicial de plantas de girassol (Helianthus annuus L.) irrigadas com água residuária. Educação Agrícola Superior, v. 22, n. 2, p. 48-50, 2007.

BISCARO G. A.; MACHADO, J. R.; TOSTA, M. S.; MENDONÇA, V.; SORATTO, R. P.; CARVALHO, L. A. Adubação nitrogenada em cobertura no girassol irrigado nas condições de Cassilândia-MS. Ciência e Agrotecnologia, v. 32, n. 5, p. 1366-1373, 2008. http://www.scielo.br/pdf/cagro/v32n5/02.pdf

COELHO, M. A.; SONCIN, N. B. Geografia do Brasil. São Paulo: Moderna. 1982, p. 368.
EMBRAPA - Empresa Brasileira de Pesquisa Agropecuária. Manual de métodos de análises do solo. 2.ed. Rio de Janeiro. Centro Nacional de Pesquisa de Solo. 1997. 212p.

FERREIRA, D. F. Sisvar: a computer statistical analysis system. Ciência e Agrotecnologia, v.35, n. 6, p.1039-1042, 2011. http://dx.doi.org/10.1590/S1413-

70542011000600001

FREITAS, C. A. S., SILVA, A. R. A., BEZERRA, F. M. L., ANDRADE, R. R., MOTA, F. S. B.; AQUINO, B. F. Crescimento da cultura do girassol irrigado com diferentes tipos de água e adubação nitrogenada. Revista Brasileira de Engenharia Agrícola e Ambiental, v. 16, n. 10, p. 1031-1039, 2012. http://dx.doi.org/10.1590/S141543662012001000001

HERPIN, U.; GLOAGUEN, T. V.; FONSECA, A. F.; MONTES, C. R.; MENDONÇA, F. C.; PIVELI, R. P.; BREULMANN, G.; FORTI, M. C.; MELF. A. J. Chemical effects on the soilplant system in a secondary treated wastewater irrigated coffee plantation - a pilot field study in Brazil. Agricultural Water Management, v. 89, n. 1, p. 105- 115, 2007. https://doi.org/10.1016/j.agwat.2007.01.001

LEITE, R. M. V. B. C.; CASTRO, C.; BRIGHENTI, A. M.; OLIVEIRA, F. A.; CARVALHO, C. G. P.; OLIVEIRA, A. C. B. Indicações para o cultivo de girassol nos Estados do Rio Grande do Sul, Paraná, Mato Grosso do Sul, Mato Grosso, Goiás e Roraima. Embrapa Soja. Londrina, PR. 2007. 4p. (Comunicado Técnico, 78).

LOBO, T. F.; GRASSI FILHO, H. Níveis de lodo de esgoto na produtividade do girassol.

Revista Ciencia del Suelo e Nutrición Vegetal, v. 7, n. 3, p. 16-25, 2007. http://dx.doi.org/10.4067/S071827912007000300002

MORALES, E. J. M.; ROSALES, E. J. M.; LÓPEZ, E. D.; LUNA, A. J. C.; ARIAS, N. M.; DE LA CRUZET, M. G. Tasa de asimilación 
neta y rendimento de girasol en función de urea y urea de liberación lenta. Agrociencia, v. 49, n. 2, p. 2015. http://hdl.handle.net/20.500.11799/38896

NOBRE, R. G.; ANDRADE, L. O.; SOARES, F. A. L.; GHEYI, H. R.; FIGUEIREDO, G. R. G.; SILVA, L. A. Vigor do girassol (Helianthus annuus L.) sob diferentes qualidades de água. Educação Agrícola Superior, v. 23, p. 58-60, 2008.

NOVAIS, R. F.; NEVES, J. C. L.; BARROS, N. F. Ensaio em ambiente controlado. In: Métodos de pesquisa em fertilidade do solo. Brasília: Embrapa. 1991. 392p. EMBRAPASEA. (Documentos, 03).

SABBAGH, M.C. Redução de porte de girassol ornamental pela aplicação de reguladores vegetais. 2008. 93 f. Dissertação (Mestrado em Fitotecnia) - Universidade Federal do Paraná, Curitiba.

SANTOS, M. J.; ARAÚJO, L. E.; OLIVEIRA. E. M.; SILVA, B. B. Seca, precipitação e captação de água de chuva no semiárido de Sergipe. Engenharia Ambiental, v. 6, n. 1, p. 55-73, 2009.

SILVA, L. T.; OLIVEIRA, M. L. A.; SACRAMENTO, D. S.; MENDONÇA, J. O.; OLIVEIRA, G. X. S.; GHEYI, H. R. Crescimento do girassol irrigado com água residuária tratada. In: I Inovagri International Meeting \& IV Workshop Internacional de Inovações Tecnológicas na Irrigação, Fortaleza - CE. Anais... Fortaleza: INOVAGRI, 2012.

SOARES, L. E.; NETO, J. V. E.; SILVA, G. G. C.; OLIVEIRA, E. M. M.; BEZERRA, M. G. S.; SANTOS, T. J. A.; DIFANTE, G. S. Crescimento e produtividade do girassol sob doses de nitrogênio e fósforo. Revista Brasileira de Agropecuária Sustentável, v. 6, n. 2, p. 19-25, 2016. http://dx.doi.org/10.21206/rbas.v6i2.326

SOUZA, R. M.; NOBRE, R. G.; GHEYI, H. R.; DIAS, N. S.; SOARES, F. A. L. Utilização de água residuária e de adubação orgânica no cultivo do girassol. Revista Caatinga, v. 23, n. 2, p. 125-133, 2010.

TALAMINI, V.; ALMEIDA, N. A.; LIMA, N. R. S.; SILVA, A. M. F.; CARVALHO, H. W. L.; SOUSA, R. C. Avaliação da qualidade física, fisiológica e sanitária de sementes de $H$. annuus introduzidas para cultivo em Sergipe. Boletim de Pesquisa / Embrapa Tabuleiros Costeiros-Aracaju, 2011. 19 p.

TRAVASSOS, K. D.; SOARES, A. L.; GHEYI, H. R.; SILVA, D. R. S.; NASCIMENTO, A. K. S.; DIAS, N. S. Produção de aquênio do girassol irrigado com água salobra. Revista Brasileira de Engenharia Agrícola Ambiental, v. 15, n. 4, p. 371-376, 2011. http://dx.doi.org/10.1590/S141543662011000400007

ZAGONEL, J.; MUNDSTOCK, C. M. Doses e épocas de aplicação de nitrogênio em cobertura em duas cultivares de girassol. Pesquisa Agropecuária Brasileira, v. 26, p. 1487-1492, 1991.

ZOBIOLE, L. H. S.; CASTRO, C.; OLIVEIRA, F. A.; OLIVEIRA JUNIOR, A. Marcha de absorção de macronutrientes na cultura do girassol. Revista Brasileira de Ciência do Solo, v. 34, n. 2, p. 425-434, 2010. http://dx.doi.org/10.1590/S010006832010000200016 